\title{
A Review of Structural Robustness with Focus on Timber Buildings
}

\author{
Johannes A. J. Huber, Mats Ekevad, Ulf Arne Girhammar, Sven Berg \\ Division of Wood Science and Engineering, Luleå University of Technology, Skellefteå, Sweden
}

Contact: johannes.huber@ltu.se

\begin{abstract}
With an increasing number of storeys, timber buildings require closer attention to structural robustness. If a building can survive unforeseen events (e.g. accidents, terrorism), lives can be saved. The literature appears to be rather limited concerning robustness of timber buildings. This paper aims to give a brief review on robustness in general and design guidelines for timber in specific. The results indicate that connection design is a key aspect for robustness. Like in seismic design, by using the ductile capacity of connectors, the brittleness of timber can be controlled. For light timber-frame buildings, more guidelines exist than for posts and beams and cross-laminated timber, which both seem to be similar to steel frames and precast concrete respectively regarding robustness.
\end{abstract}

Keywords: robustness; timber; disproportionate collapse; progressive collapse; alternate load path

\section{Introduction}

A building should provide space and protect its occupants. It should survive expected and unexpected exposures during its lifetime. Building codes can efficiently provide resistance to expected loads, but the treatment of unexpected loads is more difficult. A robust building can survive a local damage resulting from an unexpected exposure. Survival of a structure means that its protective function is sustained [1]. Large deformations may be tolerable if occupants can be saved. The research in this topic started with the case of Ronan Point (1968) where an explosion led to the collapse of a building corner in a 22-storey concrete building [2]. Other decisive events were the Murrah Building in 1995 [3] and the World Trade Center in 2001 [2], where terrorist attacks induced collapse. Since steel and concrete buildings have encountered robustness for a longer time than timber buildings have, comprehensive literature is available for the former. Recently, timber buildings have reached 18 storeys [4] and more high-rise timber buildings are being built. In Eurocode [5], taller buildings have higher consequence classes which makes the matter of robustness more acute. The literature in this respect is rather limited regarding timber buildings and in many cases design guidelines are scarce [6].

The goal of this paper is to provide a brief review of structural robustness in general and design guidelines for timber buildings in specific. We considered light timber-frames, post and beam constructions and cross-laminated timber (CLT) buildings this study. The results indicate that some knowledge regarding robustness exists for light timber-frames, and that only limited knowledge and guidelines exist for timber posts and beams and CLT buildings. 


\section{Robustness in general}

\subsection{Definitions}

To distinguish robustness from other properties, the probability of a disproportionate collapse, $P(C)$, is split into the probabilities of an unforeseen event, $P(E)$, a damage given the event, $P(D \mid E)$, and a collapse given the damage, $P(C \mid D)[7]$ :

$$
P(C)=\underbrace{P(E)}_{\text {Exposure }} \cdot \underbrace{P(D \mid E)}_{\text {Vulnerability }} \cdot \underbrace{P(C \mid D)}_{\text {Robustness }}
$$

$P(E)$ is referred to as exposure, $P(D \mid E)$ as vulnerability and $P(C \mid D)$ as robustness [7]. Damage means a partial reduction of the structural functionality of the building. Collapse can be seen equivalent to the total reduction of the structural functionality of a substantial part of a building. Vulnerability concerns a structure's resistance to damage initiation, and robustness the resistance to damage propagation, independent of the exposure [7] (see Figure 1). Structural design may affect robustness and vulnerability, but not exposure [7]. The terminology concerning robustness is ambiguous in the literature, but the general concept seems to be coherent [8]. In this paper, we regard robustness as an intrinsic structural property which describes the global tolerance to local damages, independent of the cause.

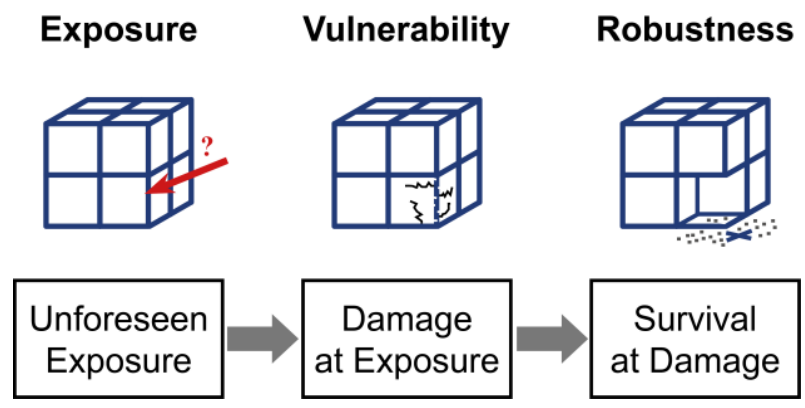

Figure 1. Robustness as a structural property

Progressive collapse describes how damage spreads in a structure, i.e. that components fail in a successive series. Disproportionate collapse describes how large the resulting damage is compared to the initial damage. Disproportionality may be defined in structural codes.

\subsection{Robustness analysis}

Analysis approaches are based on (a) total risk, (b) reliability or (c) deterministic analysis [6]. In (a), the probability of exposures, damages and consequences are considered to calculate a robustness index. In (b), the collapse probabilities of an undamaged and damaged structure are compared to calculate a robustness index. In (c), the structural response to a specific damage (i.e. scenario-independent) or an exposure (i.e. scenario-dependent) is studied to quantify robustness. The approaches (a) and (b) are probabilistic, whereas (c) is deterministic.

A common deterministic method is to investigate the response to initial damage by a notional (i.e. hypothetical) removal of load-bearing elements. After the removal, the development of alternative load paths can be studied [9]. A guideline for the removal extent is the length $2,25 H(H$ is the storey height) or the length between two vertical supports [2]. Columns inside the diameter of this length, or an analogous part of a load-bearing wall, should be removed on each storey [2]. For corners, the length $H$ should be removed in each direction. For the removal analysis, a linear static, a non-linear static, a linear dynamic or a nonlinear dynamic procedure may be used [9]. The static procedures use a dynamic load factor to account for inertial effects. The non-linear procedures may accurately model load distribution mechanisms due to plasticity, but they are computationally expensive [8]. Another procedure is the non-linear static pushover analysis, which uses the balance between the internal strain energy and the external work performed by the loads to calculate the dynamic response from the non-linear static response to increased gravity loads [10].

For deterministic quantification, we found that a binary and a continuous approach exists. In the binary approach, a building is either robust or not. The criterion is often an allowable collapse extent after a specified removal, or instead, whether certain design rules have been followed or not. Building codes usually apply the binary approach. In the continuous approach, a building can have a high or low level of robustness, depending on structural properties before and after an initial 
damage, i.e. total resulting damage, energy release after failure, stiffness of the damaged structure, reserve strength, the ductility limitstate, or several properties combined [6].

\subsection{Indirect design methods}

Indirect design means that certain design guidelines are followed without a detailed check for alternative load paths [7].

Providing ties is a method to achieve a minimum level of robustness for low-consequence buildings [8]. Ties are mechanical links between building components which should ensure continuous load paths and limit the displacement between the components [2]. After element loss, internal and peripheral horizontal ties should allow beams to act as catenaries (see 2.4) and floors to act as membranes (see 2.4), and vertical ties should allow floors to be suspended from the storey above [2].

Providing redundancy in a structure ensures the existence of alternative load paths [7]. In active redundancy, loads are always shared along these paths, and in passive (fail-safe) redundancy, loads are shared only after damage has occurred [2]. Redundancy can make a structure more robust, if the redundant members behave ductile after overload and thus enable load-sharing among them [1]. Conversely, redundancy can promote progressive collapse if the members fail brittle and cannot contribute to load-sharing after failure [2].

\subsection{Direct design methods}

Direct design makes a building survive an assumed damage, e.g. the removal of an element [7]. It explicitly checks for alternative load paths.

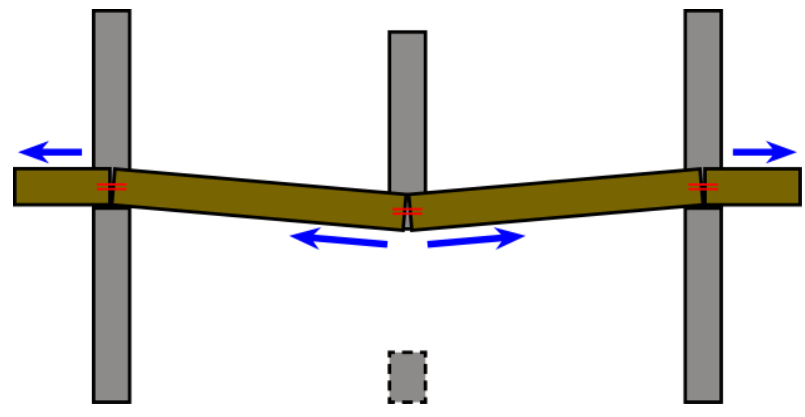

Figure 2. Catenary action

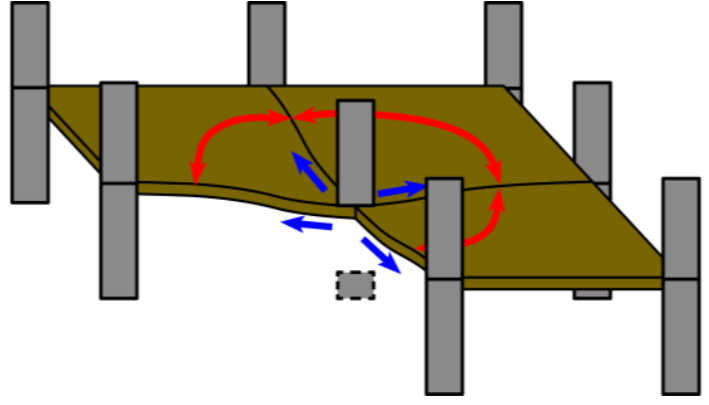

Figure 3. Membrane action

In alternative load path design, the structure should activate alternative load paths after a notional element removal [3] and satisfy any requirements for allowable collapse area. Two mechanisms of load distribution are catenary action and membrane action [8]. In catenary action, the beams above a failed element behave like a chain to support the remaining structure (see Figure 2). In membrane action, the floor slabs or diaphragms above a failed element form a membrane and support the remaining structure (see Figure 3). Both mechanisms require sufficient tensile capacity in the members and the capacity for large deformations without rupture in the connections. To develop alternative load paths, connection design is therefore a key aspect, in specific their ductile behaviour at overloads [2][3].

Compartmentalisation divides the structure into independently robust compartments [9]. A collapse should not progress among the compartments. The compartment borders can either be designed to sustain excessive loads, or they can be designed to yield at a specific load to limit the transferred forces between the compartments [7]. The collapse of a compartment may be accepted to protect the others.

In key element design, critical components should resist a specific high load [9]. Often $34 \mathrm{kPa}$ is used, which originates from explosion pressures [2]. Key elements should be the last resort, if element removal cannot be tolerated differently [8].

\subsection{Building codes}

Eurocode [5] classifies buildings into consequence classes 1, 2A, 2B and 3 for robustness. Class 1 requires no provisions, class $2 A$ requires horizontal tying, class $2 \mathrm{~B}$ additionally requires vertical tying, and class 3 additionally requires a 
systematic risk assessment. The required tie forces depend on the building, but for framed buildings, horizontal tie forces need to be at least $75 \mathrm{kN}$. For timber, the UK's national annex to Eurocode [11] allows for a reduction of internal and peripheral horizontal tie forces to $1 / 10$ and to $1 / 5$ respectively. For class $2 \mathrm{~B}$, alternatively notional element removal may be used. The resulting damage extent must be smaller than 100 $\mathrm{m}^{2}$ or $15 \%$ of the floor area, in each of two adjacent storeys. If this limit cannot be met, key elements should be used.

The U.S. codes for progressive collapse [12][13] classify buildings into risk categories I to IV. Category I requires no provisions. Category II requires either key elements in the building corners on the first storey plus horizontal and vertical ties, or a proof that the structure can bridge gaps after the removal of specified elements. Category III requires key elements on the perimeter of the first storey plus the removal of specified elements. Category IV additionally requires horizontal and vertical ties. The tie forces depend on the building and ties need to be able to rotate a certain angle. Unlike the Eurocodes, the U.S. codes give detailed guidance on how to perform the element removals for different building types.

\section{Robustness in timber buildings}

\subsection{General issues}

Collapse analyses have been focused on largespan timber buildings and human error has been identified as the main reason of unexpected failures [14]. Timber has a relatively low density compared to its stiffness and strength. Therefore, lower inertial effects compared to other building materials could be expected during collapse. Timber fails in a brittle mode under tension, bending and shear, but it exhibits some ductility in compression [15]. There exist robustness analyses based on the reliability approach, often for hall buildings [16], but deterministic robustness analyses of timber buildings have been more difficult to find.

The connections need to be designed with care to avoid brittle failure in timber structures after a failure. Plastic yielding of metal connectors together with compressive failure of the wood are the main sources of ductility in timber connections [15]. In capacity-based design, the connectors are designed to yield in a ductile manner before brittle failure can occur in the timber components [17]. A safety margin, called overstrength factor, is used to assure this behaviour [18]. A similar approach of channelling failure to specific ductile parts of the structure is also used in seismic design of timber buildings [19]. Seismic connectors also need to provide ductility to absorb large deformations and dissipate energy.

In the following, three types of timber construction types are reviewed. Information regarding buildings made of prefabricated timber modules could not be found. However, we think that prefabrication under controlled industrial conditions could decrease the probability of human error, resulting in positive effects on robustness.

\subsection{Light timber-frame construction}

Buildings of this type consist of wooden frames joined by screws and nails. The frames constitute vertical shear walls and horizontal diaphragms, which both can behave ductile under in-plane loading [15]. In the Timber Frame 2000 (TF2000) project in 1998, internal and external walls were removed from a six-storey platform light timberframe test building [8]. The results led to design guidelines for robustness and an understanding of the load-distributing mechanisms after a removal.

For class 2A light timber-frame buildings, Eurocode's tie force requirements may be difficult to achieve, and thus effective anchorage between the components is often recommended instead [2]. Effective anchorage means a minimum fixing density, e.g. $3,1 \mathrm{~mm}$ diameter nails with $300 \mathrm{~mm}$ spacing for all horizontal interfaces [2]. For class $2 \mathrm{~B}$ buildings, notional element removal should be preferred over implementing tying requirements [2]. If effectively anchored to the structure, the shear walls may act as deep beams above gaps (see Figure 4), and the floor diaphragms may act as membranes or cantilevers over removed walls [2]. 


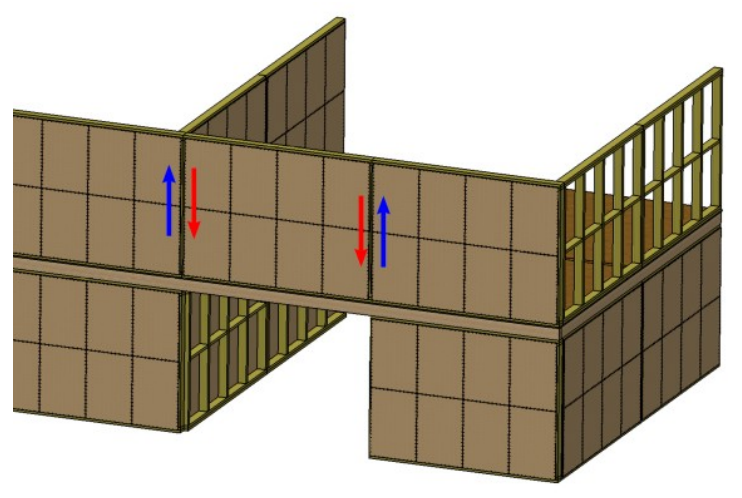

Figure 4. Deep beam action in a light timber-frame

Rim beams can increase the bridging capacity of a light timber-frame building after the removal of a wall panel. Rim beams are usually made of engineered timber, e.g. glued laminated timber, and they run continuously on top of internal and peripheral walls (see Figure 5), on each storey [20]. The walls and floors attached to the rim beam should be well anchored to it, such that it can transfer the loads in the structure after a loss [2].

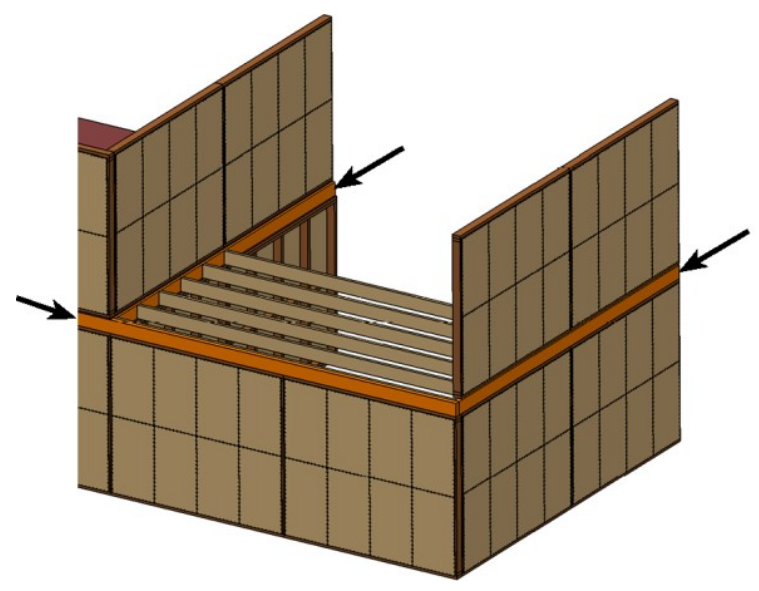

Figure 5. Rim beam indicated by arrows

\subsection{Post and beam construction}

Buildings of this type consist of a main frame made of vertical posts and horizontal beams, often made of engineered wood products. In certain aspects, this construction type is similar to steel frames regarding robustness. Timber posts and beams are usually designed for tie force requirements [20], like steel frames [2]. Both building types should enable catenary action after element removal. However, compared to steel, timber beams require an overstrength towards their connections to enable ductile yielding [20]. Unlike timber, steel beams may develop plastic hinges also internally, outside the connections [9].

The floors in both steel frames and post and beam constructions may, if they are sufficiently anchored to the frame, develop membrane action after the removal of a column [20]. If the floors can span in two directions, e.g. by using CLT (see 3.4), this effect could be enhanced. Similarly, walls which are sufficiently anchored to the frame could act as deep beams over gaps or as cantilevers in corners.

A failure in the bracing system, both under and after construction, is critical for posts and beams [14] and steel frames. The notional removal of the bracing elements should therefore be considered when evaluating robustness [8]. To enhance the stability of a steel frame after a bracing failure, redundant bracing elements should exist [2]. Redundant bracing could also be used for timber posts and beams, e.g. by using moment-resisting connections, shear walls in the frame, or rigid cores for stairs and lifts. The shear walls could be made of CLT (see Figure 6).

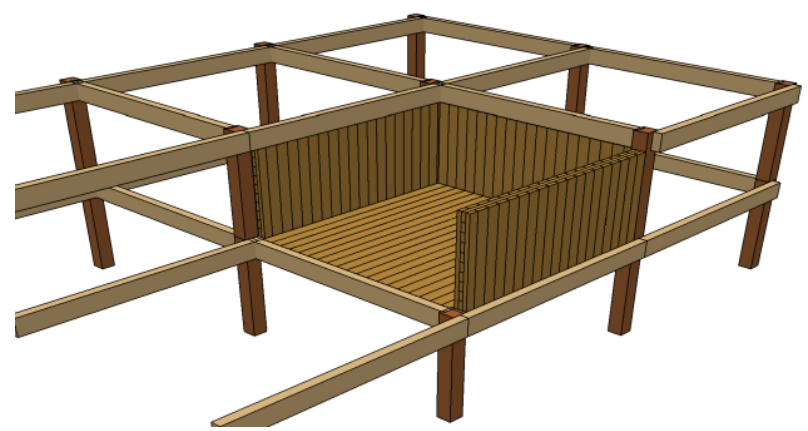

Figure 6. CLT panels in a post and beam structure

Large-span timber buildings, e.g. hall buildings, should be designed by compartmentalisation (see 2.4), to limit the collapsed area [15]. The idea is to allow a part of the structure to disconnect from the rest, so that the remaining part can survive.

\subsection{Cross-laminated timber}

CLT consists of solid wood boards, glued together in perpendicular layers of parallel boards, and it may support loads in plane and out of plane [21]. Due to its layup, CLT can span in two perpendicular directions. CLT is used as both walls and floors. They may form a balloon frame 
structure with walls spanning several storeys, or a platform structure with walls spanning one storey and floors anchored on top of each wall [21].

Currently, design guidelines for CLT regarding robustness are scarce [22]. In general, it seems unclear how to implement ties in CLT buildings [8]. If the element removal method is used, the forces required from a CLT structure may be generally lower than if the tying forces from codes are considered [20]. Panelised precast concrete buildings are like CLT buildings in their structural form. For precast concrete, robustness relies on effective ties, which anchor the components together, either by friction between walls and floors, or by in situ cast metal links [2]. Load distribution effects in a CLT structure after the removal of an element may be walls acting as deep beams (see Figure 7) and floors acting as membranes [20]. The behaviour after the removal may be similar to that of precast concrete floors and walls, which can exhibit deep beam and membrane action if they are sufficiently well connected to the remaining structure [2].

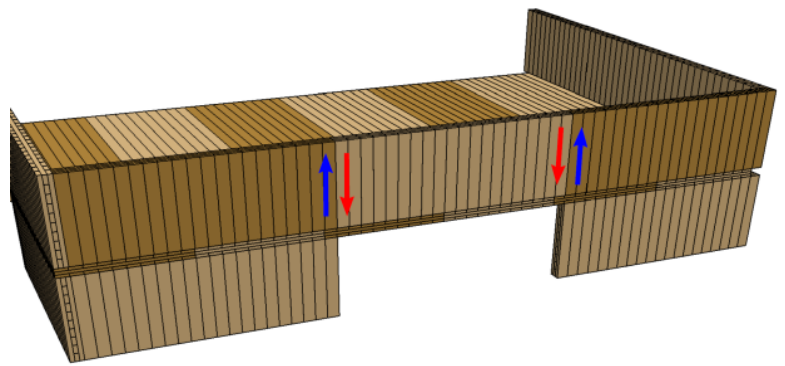

Figure 7. Deep beam action in a CLT building

The connections are critical to enable the desired effects in CLT buildings. For deep beam action, the wall-to-wall and the floor-to-wall connections need to have sufficient strength capacity. For membrane action, the floor-to-wall and the floorto-floor connections need to have sufficient tensile and deformation capacity. Ductility in the connections can avoid brittle component failure, like for connections in precast concrete [9].

\subsection{Design Cases}

A few design cases regarding robustness are available for tall timber buildings. The Stadthaus in London, a 9-storey platform CLT building, was designed for the removal of a single wall or floor panel, and for a shock load of 7,5 kPa [23]. Four 9storey platform CLT buildings in Milan, Italy, were designed for the removal of the length of an entire wall panel [24]. A theoretical study of the removal of an internal wall in a simple 12-storey CLT building suggests that standard angle brackets and self-tapping screws used in CLT might not meet the demands for robustness [22].

The 18-storey UBC Brock Commons Building in Vancouver was designed to tolerate the removal of one of its glulam columns between its CLT floors and to let the damaged area hang from the remaining columns above [25].

The 18-storey $(81 \mathrm{~m})$ Mjøstårnet, which is currently being built in Brumunddal in Norway, is designed with large glulam columns, horizontal beams and diagonal beams for stabilisation [26]. Its lower floors are made of glulam floor cassettes and its upper floors are made of concrete slabs. The design considered the removal of the diagonal beams and the removal of the support for the concrete floors including the resulting impact load of a falling concrete floor. The glulam columns were designed as key elements, tolerating at least the required $34 \mathrm{kPa}$, and the connections were designed ductile, i.e. dowel yielding in the slottedin steel plates (Bjertnæs M. A., personal communication).

The 23-storey $(84 \mathrm{~m}) \mathrm{HoHo}$ in Vienna, which is currently being built, is a timber-concrete hybrid construction with connections specifically designed to provide horizontal and vertical ties. Its glulam columns are vertically tied with glued-in steel rods which connect to steel jackets in the peripheral precast concrete beams, and its floors are horizontally tied to the beams by cast-in reinforcement bars [27]. The ties are established by casting in the connections with grout at site. The $\mathrm{HoHo}$ is designed to tolerate the loss of one column and distribute the loads on the remaining columns via a continuous precast concrete beam [27].

\section{Discussion and conclusions}

Robustness is an intrinsic structural property which describes the global survival tolerance to local damages, independent of the cause. To analyse robustness, certain structural elements 
can be notionally removed, and the resulting damage can be compared to any given thresholds. To provide robustness, direct and indirect methods can be used. Indirect methods prescribe design solutions, but they don't check the effects of these measures in damage scenarios. Directs methods consider a certain damage, most often the removal of an element. Connections are critical to enable load distribution effects after damage. Catenary and membrane action rely on sufficient strength and deformation capacity in the connectors. In timber buildings, ductile metal connectors can avoid brittle failure if they yield before the strength of the timber is reached, like in seismic design.

There are some design guidelines for robustness of light timber-frame buildings, but only few for timber posts and beams and CLT, and none for prefabricated modules. In light timber-frames, the walls and floors should be effectively anchored to enable deep beam and membrane action. A rim beam can be used to improve the design. Post and beam constructions are like steel frames in certain aspects. They should be designed with ties, but the ductile connection behaviour needs verification to enable catenary action. A redundant bracing system, e.g. by momentresisting connections, timber shear walls or rigid building cores, could improve the survival after a bracing failure. CLT floor and wall panels, like precast concrete panels, should be anchored to each other to enable deep beam action and membrane action after an element removal. For membrane action, the deformation capacity of the connections may require explicit checks. In practical design cases for CLT, the notional removal of a wall has been preferred over the tying method. For pure CLT structures, we could not find any examples of the tying method.

Future research should address the design of CLT buildings, posts and beams and prefabricated modules regarding robustness. In specific, the strength and deformation capacity of the connections after an element removal should be investigated. Furthermore, there is a need to develop methods to implement horizontal and vertical ties in pure CLT structures, e.g. platformframed buildings. Although some practical design examples regarding robustness of tall timber buildings could be found, in general more descriptions of the practice are needed. Sharing knowledge and insights will be valuable for designing safe and structurally robust multi-storey timber buildings in the future.

\section{Acknowledgements}

We express our thanks to the Vinnova Biolnnovation project which funded this study.

\section{References}

[1] Knoll F., and Vogel T. Design for Robustness. Zurich: International Association for Bridge and Structural Engineering (IABSE); 2009.

[2] The Institution of Structural Engineers. Practical guide to structural robustness and disproportionate collapse in buildings. London: Institution of Structural Engineers; 2010.

[3] Byfield M., Mudalige W., Morison C., et al. A review of progressive collapse research and regulations. Proceedings of the Institution of Civil Engineers - Structures and Buildings. 2014; 167(8): 447-456.

[4] Fast P., Gafner B., and Jackson R. Eighteen Storey Hybrid Mass Timber Student Residence at the University of British Columbia. Structural Engineering International. 2017; 27(1): 44-48.

[5] European Committee for Standardization. EN 1991-1-7:2006. Eurocode 1 - Actions on structures - Part 1-7: General actions Accidental actions; 2006.

[6] Huber J. A. J., Ekevad M., Girhammar U. A. et al. Structural robustness and timber buildings - a review. Wood Material Science \& Engineering. 2018; DOI: 10.1080/17480272.2018.1446052, advance online publication.

[7] Starossek U., and Haberland M. Disproportionate Collapse: Terminology and Procedures. Journal of Performance of Constructed Facilities. 2010; 24(6): 519-528.

[8] Arup. Review of International Research on Structural Robustness and Disproportionate 
Collapse. London: Department for Communities and Local Government; 2011.

[9] Ellingwood B. R., Smilowitz R., Dusenberry D. et al. Best practices for reducing the potential for progressive collapse in buildings. National Institute of Standards and Technology - Technology Administration - U.S. Department of Commerce, NISTIR 7396; 2007.

[10] Izzuddin B. A., Vlassis A. G., Elghazouli A. Y. et al. Progressive collapse of multi-storey buildings due to sudden column loss - Part I: Simplified assessment framework. Engineering Structures. 2008; 30(5): 13081318.

[11] British Standards Institution. NA to BS EN 1991-1-7:2006. National Annex to Eurocode 1: Actions on structures - Part 1-7: Accidental actions; 2008.

[12] General Services Administration. Alternate Path Analysis \& Design Guidelines for Progressive Collapse Resistance. General Service Administration; 2013.

[13] U.S. Department of Defense. Unified Facilites Criteria (UFC) - Design of Buildings to Resist Progressive Collapse. U.S. Department of Defense, UFC 4-023-03; 2016.

[14] Frühwald Hansson E. Analysis of structural failures in timber structures: Typical causes for failure and failure modes. Engineering Structures. 2011; 33(11): 2978-2982.

[15] Thelandersson S., and Honfi D. Behaviour and modelling of timber structures with reference to robustness. In: Köhler J., Narasimhan H., and Faber M. H., editors. Proceedings of the Joint Workshop of COST Actions TU0601 and E55; 21-22 Sept 2009; Ljubljana, Slovenia. Brussels: COST Office; 2009. 125-138.

[16] Kirkegaard P. H., and Sørensen J. D. Collapse Analysis of Timber Structures. In: Topping B. H. V., and Papadrakakis M., editors. Proceedings of the Ninth International Conference on Computational Structures Technology; 2-5 Sept 2008; Athens, Greece.
Stirlingshire, Scotland: Civil-Comp Press; 2008. Paper 247.

[17] Jorissen A., and Fragiacomo M. General notes on ductility in timber structures. Engineering Structures. 2011; 33(11), 29872997.

[18] Brühl F., Schänzlin J., and Kuhlmann U. Ductility in Timber Structures: Investigations on Over-Strength Factors. In: Aicher S., Reinhardt H.-W., and Garrecht H., editors. Materials and Joints in Timber Structures. Dordrecht: Springer Netherlands, 2014; 181-190.

[19] Branco J. M., and Neves L. A. C. Robustness of timber structures in seismic areas. Engineering Structures. 2011; 33(11): 30993105.

[20] Hewson N. Robustness in Structures. Forest and Wood Products Australia Limited; 2016.

[21] Gagnon S., and Pirvu C., editors. CLT Handbook: Cross-Laminated Timber. Canadian ed. Québec: FPInnovations; 2011.

[22] Mpidi Bita H., Currie N., and Tannert T. Disproportionate collapse analysis of midrise cross-laminated timber buildings. Structure and Infrastructure Engineering. 2018; advance online publication, DOI: 10.1080/15732479.2018.1456553.

[23] Wells M. Tall Timber Buildings: Applications of Solid Timber Construction in Multistory Buildings. Council on Tall Buildings and Urban Habitat Journal. 2011; 2011(I): 24-27.

[24] Bernasconi A. Four Residential Towers As CLT Timber Construction in the City of Milan. In: Eberhardsteiner J. et al., editors. World Conference on Timber Engineering 2016, 22-25 August 2016; Vienna. Vienna: TU Verlag; 2016. 5771-5778.

[25] Mpidi Bita H., and Tannert T. Robustness of Multi-Storey Timber Buildings. $39^{\text {th }}$ IABSE Symposium: Engineering the Future; 21-23 September 2017; Vancouver, Canada. IABSE; 2017. 1926-1933.

[26] Abrahamsen R. Mjøstårnet - Construction of an $81 \mathrm{~m}$ tall timber building. 23. 
Internationales Holzbau-Forum IHF 2017, 68 December 2017; Garmisch-Partenkirchen. 1-13.

[27] Woschitz R., and Zotter J. High-rise Timber Building HoHo Vienna - The structural Concept. Österreichische Ingenieur- und Architekten-Zeitschrift. 2017; 162(1-12): 6368. 